\title{
UMA PROPOSTAS DE EDUCAÇÃO AMBIENTAL NO MUNICÍPIO DE CABO FRIO (RJ)
}

\author{
Sandro Carlos Pereira ${ }^{1}$ \\ Regina Célia Soares Pereira ${ }^{2}$ \\ Izabella Valadão ${ }^{3}$
}

Resumo: A destinação inadequada dos Resíduos Sólidos Urbanos (RSU) representa um grave problema socioambiental. Um dos possíveis caminhos para o enfrentamento deste problema é a Educação Ambiental crítica. O presente estudo tem como objetivo implantar um projeto de Educação Ambiental para sensibilizar os estudantes em relação a realidade socioambiental do município de Cabo Frio-RJ. Foram realizadas quatro oficinas pedagógicas com 12 (doze) estudantes do $3^{\circ}$ ano do Instituto de Educação Professora Ismar Gomes de Azevedo (IGA), colégio estadual. Ao final, percebeu-se que a Educação Ambiental crítica propicia aos estudantes a construção de uma prática educativa e reflexiva sobre seus comportamentos em relação ao meio ambiente e também em relação à sociedade.

Palavras-chave: Práticas Educativas; Oficinas Pedagógicas; Atividade Vivencial; Projetos Educacionais.

${ }^{1}$ Blueway Consultoria. E-mail: sandropereira050@gmail.com

${ }^{2}$ Colégio Pedro II - RJ. E-mail: rsoarespereira7@gmail.com

3 Universidade Veiga de Almeida. E-mail: izavaladao5@gmail.com 


\section{Introdução}

Localizado no estado do Rio de Janeiro, na Região dos Lagos, o município de Cabo Frio, conforme aponta o Instituto Brasileiro de Geografia e Estatística (IBGE, 2014) possui uma área territorial de $410.418 \mathrm{~km}^{2}$, população estimada de 204.486 habitantes e com Índice de Desenvolvimento Humano Municipal igual a 0,735.

De acordo com a Prefeitura Municipal de Cabo Frio (PMCBF, 2016), a Praia do Forte, com extensão litorânea de $7,5 \mathrm{~km}$, é a mais conhecida de Cabo Frio. Banhada por águas transparentes e cristalinas é considerada um dos cartões-postais do Estado do Rio de Janeiro. Em sua extrema esquerda fica o Forte São Mateus, construção portuguesa do século XVII, e à direita fica a Praia das Dunas.

Dados da Prefeitura Municipal de Cabo Frio (PMCBF, 2014) indicam que, na virada do ano e durante a alta temporada no verão, mais de um milhão de turistas passam pela cidade ocupando $100 \%$ da rede hoteleira.

O período de alta temporada se caracteriza pelo aumento expressivo na geração de resíduos sólidos Urbanos (RSU) na cidade. Segundo Brum (2015) é preciso unir forças em prol de uma formação educacional que sensibilize as pessoas no sentido de conhecer e preservar as riquezas naturais, evitando os agravos ambientais provocados pela geração excessiva de RSU.

A Lei 9795/99 (BRASIL, 1999), no capítulo 1, art. 1, define Educação Ambiental como os processos por meio dos quais o indivíduo e a coletividade constroem valores sociais, conhecimento, habilidades, atitudes e competências voltadas para a conservação do meio ambiente, bem de uso comum do povo, essencial à sadia qualidade de vida e sua sustentabilidade.

Desde 2012, a Secretaria Municipal de Educação (SEME) de Cabo Frio define as diretrizes curriculares municipais para a Educação Ambiental, com base na Constituição Federal da Lei de o 9.394/96, que estabelece as Diretrizes e Bases da Educação Nacional, e da Lei no 9.795/99, que institui a Política Nacional de Educação Ambiental.

De acordo com dados do Instituto Nacional de Estudos e Pesquisas Educacionais (INEP, 2015) a cidade possui 95 escolas de ensino fundamental, sendo 59 escolas municipais, 09 escolas estaduais e 27 escolas privadas com o total de 29.882 alunos matriculados.

Segundo Guimarães (2004), a Educação Ambiental pode ser descrita de duas formas: a educação conservadora que fragmenta a realidade e não está comprometida com o processo de transformação; e a educação crítica que ocorre para além dos muros da escola e gera uma interface entre a Educação Ambiental e a educação popular. Sobretudo, a proposta pedagógica da Educação Ambiental crítica é o desenvolvimento de projetos fora da sala de aula formal e que tenha como prática o caráter educativo crítico.

A partir destes cenários e considerando a tendência do aumento no número do fluxo de turistas domésticos e internacionais na cidade de Cabo

revista brasileira educação ambiental 
Frio, a destinação inadequada dos RSU representa um grave problema ambiental que precisa ser enfrentado pela sociedade civil. Um dos possíveis caminhos para o enfrentamento deste problema é a Educação Ambiental.

O objetivo deste estudo é implantar um projeto de Educação Ambiental tendo como público alvo estudantes do $3^{\circ}$ ano do ensino médio de uma escola técnica de formação de professores.

\section{Metodologia}

Este estudo utiliza um conjunto de recursos metodológicos, organizados para permitir a criteriosa observação, interpretação e explicação dos fenômenos estudados, a fim de alcançar o objetivo proposto. Os métodos e instrumentos estão descritos nas quatro etapas seguintes:

Etapa 1: Revisão bibliográfica com base na busca realizada, no ano de 2016, nos portais SciELO, Google Acadêmico e Birene. Foram utilizadas as palavras-chave Cabo Frio, resíduos sólidos e Educação Ambiental, ambas nas versões em português e inglês.

Etapa 2: Vincular o projeto de Educação Ambiental as diretrizes curriculares do Município de Cabo Frio - RJ (SEME, 2012);

Etapa 3: Utilizar a metodologia do Ciclo de Atividade Vivencial (CAV) para o desenvolvimento de 04 oficinas pedagógicas, ressaltando a importância da reutilização de resíduos sólidos;

Etapa 4: Analisar as percepções dos estudantes do $3^{\circ}$ ano do ensino médio em relação a execução do projeto, através do questionário aplicado aos alunos pelas orientadoras na escola. Trata-se de uma pesquisa qualitativa que usa como instrumento o questionário para levantamento de dados. Conforme afirma Casarin (2012), a pesquisa qualitativa envolve a descrição de fenômenos e da análise do contexto no qual o objeto da pesquisa está inserido.

\section{Levantamentos}

\section{O cenário de desenvolvimento da pesquisa}

Motta e Terra (2011) lembram que o município de Cabo Frio foi descoberto em 1503, na ocasião da passagem do navegador Américo Vespúcio pelo Brasil. A presença de pau brasil atraía a presença de navegadores portugueses, ingleses, franceses e holandeses em busca de riquezas. As igrejas e convento são uma marca histórica da tentativa de Portugal controlar o modo de produção social do local. No entanto, segundo a Prefeitura Municipal de Cabo Frio, a cidade foi fundada oficialmente em 13 de novembro de 1615. O nome da cidade está relacionado ao acidente geológico "Cabo", enquanto que o termo "Frio" se refere às frias correntes marinhas da região e dos ventos nordeste que sopram constantemente ao longo do ano. 
O local onde este estudo acontece é na região do entorno do Parque Estadual Costa do Sol, em Cabo Frio, na Estrada Caminho de Búzios, 2.700. Nesta área existem 02 edificações: um galpão que é utilizado como sala de aula e uma capela que abriga obras de artes dos artistas locais. Segundo Massari (2005), as construções pertencem a Organização Não Governamental (ONG), registrada com o nome de Obra Missionária de Apoio (OMDA) que é uma associação sem fins lucrativos, com objetivo de desenvolver ações socioambientais.

Brum (2015) destaca que os patrimônios ambientais e culturais da cidade necessitam ser conhecidos para serem preservados, e desta forma manter acesa a identidade ambiental e cultural que tornam Cabo Frio a sétima cidade mais antiga do Brasil e uma das mais belas do mundo.

\section{Resíduos sólidos urbanos nas regiões litorâneas}

A geração dos resíduos sólidos urbanos na região litorânea, como em todo o Brasil, apresenta muitos desafios a serem superados. De acordo com a Associação Brasileira de Empresas de Limpeza Pública e Resíduos Especiais (ABRELPE, 2015), a redução de resíduos úmidos dispostos em aterros sanitários deverá ser de $38 \%$ até 2023 , com base na caracterização nacional de 2013. Outro ponto de destaque é que, segundo dados do Programa Estadual de Resíduos Sólidos do Rio de Janeiro (PERS/RJ, 2014), são despejadas 278 toneladas por dia de resíduos sólidos urbanos no aterro sanitário Arranjo Lagos II, localizado no Município de São Pedro da Aldeia, cidade vizinha de Cabo Frio.

Vale ressaltar, que a Política Nacional de Resíduos Sólidos (PNRS), Lei no 12.305 de agosto de 2010, no capítulo 2, artigo 3, define como geradores de resíduos sólidos: pessoas físicas ou jurídicas, de direito público ou privado, que geram resíduos sólidos por meio de suas atividades, nelas incluído o consumo de produtos.

A Lei Orgânica do Município de Cabo Frio (LOMCB, 1990), publicada em 20/04/1990, em seu artigo 160, assegura o direito à qualidade de vida e à proteção do meio ambiente, devendo zelar pela utilização racional e sustentada dos recursos naturais e, em particular, pela integridade do patrimônio ecológico, genético, paisagístico, histórico, arquitetônico, cultural e arqueológico.

\section{Um breve histórico sobre os movimentos sociais de Educação Ambiental no Mundo e no Brasil}

De acordo com Pereira (2014), vários movimentos sociais relacionados às questões ambientais ocorreram na década de 70 , entre estes a chamada "Carta de Belgrado", que surge como um elemento importante de tentativa de combate à crise socioambiental mundial. Ainda nesta mesma década ocorre em Tibilise, na Geórgia, a Conferência Intergovernamental sobre Educação

revista brasileira educação ambiental 
Ambiental, onde meio ambiente envolve um conceito mais amplo que remete tanto ao espaço físico, biótico, quanto ao social e cultural.

Ainda segundo Pereira (2014), a primeira tentativa de formular um documento que conceituasse a formação em Educação Ambiental surge na década de 80, no Congresso Internacional de Moscou, em 1987.

Os dois mais importantes marco histórico no Brasil aconteceram na ocasião da Conferência das Nações Unidas sobre Meio Ambiente e Desenvolvimento Humano, conhecida como Rio/92 e vinte anos depois acontece a conferência RIO + 20. Considerada como uma segunda etapa, teve como objetivo o desenvolvimento sustentável do planeta, e onde foi apresentado o documento assinado por 190 países, denominado "Futuro que queremos".

\section{As diretrizes curriculares para a Educação Ambiental do município de Cabo Frio}

De acordo com a SEME (2012), as Diretrizes Curriculares Municipais para a Educação Ambiental são princípios fundamentos e procedimentos que orientam o planejamento curricular nas escolas para a Educação Básica. A seguir são apresentadas seis Diretrizes Curriculares de Cabo Frio:

1. Estímulo à visão complexa da questão ambiental, a partir das interações dinâmicas entre ambiente, cultura e sociedade (SEME, 2012);

2. Abordagem da Educação Ambiental com uma dimensão sistêmica, multidisciplinar, interdisciplinar e transdisciplinar, de forma contínua e permanente em todas as áreas de conhecimento (SEME, 2012);

3. Abordagem crítica dos aspectos constituintes e determinantes da dinâmica da hidrosfera, atmosfera, biosfera, sociosfera e tecnosfera, contextualizando os conhecimentos a partir da dinâmica da paisagem (SEME, 2012);

4. Incentivo à pesquisa e à apropriação de instrumentos técnicos e metodológicos que aprimorem a cidadania ambiental (SEME, 2012);

5. Valorização da diversidade sob a ótica da Educação Ambiental, trazendo os múltiplos saberes e olhares científicos, de povos originários e tradicionais sobre o meio ambiente (SEME, 2012);

6. Inserção da Educação Ambiental no Projeto Político Pedagógico das unidades escolares de ensino (SEME, 2012).

Segundo Figueiró (2016), um dos maiores desafios da Educação Ambiental é possibilitar que os seres humanos continuem ocupando um espaço no planeta com algum grau de humanidade. Nesta perspectiva, a aplicação da Educação Ambiental voltada para atividades práticas relacionadas à realidade socioambiental dos estudantes podem contribuir com a formação de cidadãos críticos e para a preservação do meio ambiente.

Revbea, São Paulo, V. 13, № 2: 372-387, 2018. 


\section{Etapa 2 -Vincular o projeto de Educação Ambiental as diretrizes curriculares do Município de Cabo Frio - RJ}

Oliveira (2006) afirma que a metodologia de projeto possibilita o desenvolvimento do trabalho acadêmico em consonância com conceitos teóricos, experimentação prática e vivência intelectual, ambas incorporadas à ideia do "aprender fazendo".

O Quadro 1 apresenta as correlações entre as oficinas pedagógicas propostas no projeto de Educação Ambiental e as diretrizes curriculares de Cabo Frio.

Quadro 1: Correlação entre as oficinas e as diretrizes curriculares de Cabo Frio.

\begin{tabular}{|c|c|c|}
\hline № & $\begin{array}{l}\text { Projeto de Educação } \\
\text { Ambiental } \\
\text { (Oficinas Pedagógicas) }\end{array}$ & $\begin{array}{l}\text { Diretrizes curriculares de Educação Ambiental de Cabo Frio } \\
\qquad(\text { SEME, 2012) }\end{array}$ \\
\hline 1 & $\begin{array}{l}\text { Jogos computacionais de } \\
\text { Educação Ambiental }\end{array}$ & $\begin{array}{l}\text { Aplicar as tecnologias da comunicação e da informação na } \\
\text { escola, no trabalho e em outros contextos relevantes para } \\
\text { sua vida. }\end{array}$ \\
\hline 2 & Jogos colaborativos & $\begin{array}{l}\text { Incentivo a uma visão de mundo baseada no reconhecimento } \\
\text { e respeito das diferenças, e na cooperação, democracia, } \\
\text { justiça social, liberdade e sustentabilidade. }\end{array}$ \\
\hline 3 & Contação de histórias & $\begin{array}{l}\text { Compreender e usar a língua portuguesa como língua } \\
\text { materna, geradora de significação e integradora da } \\
\text { organização do mundo e da própria identidade. }\end{array}$ \\
\hline 4 & $\begin{array}{l}\text { Atividade prática de } \\
\text { plantio }\end{array}$ & $\begin{array}{l}\text { Proporcionar aos alunos uma grande diversidade de } \\
\text { experiências e ensinar formas de participação para que } \\
\text { possam ampliar a consciência sobre as questões relativas ao } \\
\text { meio ambiente. }\end{array}$ \\
\hline
\end{tabular}

SEME (2012) afirma que os estudantes ao vivenciarem atividades interativas de oficinas pedagógicas, referentes a sua realidade socioambiental, desenvolvem visão mais ampla de novos conhecimentos e reconhecimento da perspectiva ambiental.

\section{Etapa 3 - Ciclo de Atividade Vivencial (CAV)}

A metodologia do Ciclo de Atividade Vivencial desenvolvida por Kolb (1984), é um processo que ocorre em quatro fases distintas: a experiência concreta, a observação reflexiva, a concepção abstrata e a experimentação ativa.

Oliveira e Sauaia (2011) ao descreverem as fases do CAV sugerem que na primeira fase o estudante tenha uma experiência concreta $(E C)$ em relação ao objeto de estudo; na segunda fase ocorre o entendimento da experiência por meio da observação reflexiva (OR); na terceira fase ocorre a concepção 
abstrata (CA), trata-se da capacidade de integrar suas observações de forma lógica em teorias que descrevam a experiência concreta; na última fase, na experimentação ativa (EA) o estudante deverá usar estas teorias pra resolver problemas e tomar decisões. Iniciando-se um novo ciclo de atividades. A seguir são apresentadas as quatro oficinas pedagógicas desenvolvidas com base nas diretrizes curriculares de Cabo Frio:

\section{Jogos computacionais de Educação Ambiental}

Segundo Pereira (2014), os jogos computacionais quando adequadamente planejados e em consonância com a temática de estudo, levam à aprendizagem de diversos conceitos, possibilitando a reflexão, a discussão e sensibilização em relação às questões socioambientais.

Os dois jogos computacionais (Quebra cabeças de troca e Jogo da memória) utilizados nesta oficina pedagógica empregam o software JClick. $\mathrm{O}$ objetivo é estimular por meio de jogos computacionais o cuidado com o meio ambiente.

\subsection{Dinâmicas de grupos colaborativas}

Para Mayer (2007), as dinâmicas de grupos estimulam as pessoas a agirem e perceberem o mundo de forma diferente, justamente por ser um excelente instrumento de interação humana, de múltiplas relações interpessoais, com o propósito de buscar soluções para problemas que são comuns a todos. A intenção é utilizar dinâmicas de grupo para promover a reflexão sobre atitude e comportamentos ligados à vida em sociedade e ao cuidado com o meio ambiente.

O objetivo deste jogo é que a equipe seja capaz de realizar a destinação adequada dos resíduos sólidos. Os participantes devem levar os blocos de madeira, que representam os diversos tipos de resíduos, até o destino final utilizando um pedaço de corda.

\section{Oficina de contação de histórias}

Pastorello e colaboradores (2015) verificaram que é possível usar a "contação de histórias" como prática pedagógica para despertar nas crianças e jovens o interesse pela leitura. A arte de contar histórias é uma das atividades humanas mais antigas, com surgimento no período conhecido como préhistória e, ainda nos dias atuais, tem imensa importância na transmissão de ideias, conceitos e valores, principalmente diante do processo de ensinoaprendizagem.

Objetivo específico: Incentivar a leitura e a Educação Ambiental por meio de histórias contadas e ilustradas por Valadão (2015) com base no manual: Tijolo ecológico com reaproveitamento de resíduos. 


\section{Atividade prática de plantio}

Ao descreverem a experiência realizada com horta escolar, no estado do Espírito Santo, envolvendo um projeto interdisciplinar, Rezende e colaboradores (2014) afirmam que os alunos ao aprenderem a cultivar uma horta dentro de uma proposta pedagógica educativa desenvolvem visão mais crítica em relação ao trabalho do homem do campo, assim como também se tornam mais sensíveis e atuantes em relação as questões socioambientais da sua cidade.

O objetivo é possibilitar o contato com a terra, plantas e sobre cuidado com o meio ambiente.

\section{Etapa 4 - O questionário}

O instrumento está estruturado com as seguintes perguntas: Qual é a sua Idade e Sexo? Você percebe diferença na paisagem das praias da cidade em épocas de alta e baixa temporada? Que atitudes você acha que as pessoas deveriam tomar para melhorar esta situação? Após a visita ao projeto você percebeu alguma mudança de atitude sua em relação ao meio ambiente?

\section{Resultados}

Foi realizado o projeto de Educação Ambiental com alunos do $3^{\circ}$ ano do Instituto de Educação Ismar Gomes de Azevedo (IGA), escola estadual de formação de professores, localizada no bairro Centro, em Cabo Frio/RJ. Para tal, foram convidados 12 (doze) alunos da turma 3002, do ano letivo de 2016, que chegaram acompanhados de uma professora e duas orientadoras educacionais. Após serem recepcionados, os estudantes foram separados em 4 equipes e posteriormente convidados a participarem das oficinas pedagógicas mostradas a seguir:

\section{Jogos computacionais de Educação Ambiental}

A Figura 1 mostra os estudantes na oficina de jogos computacionais.

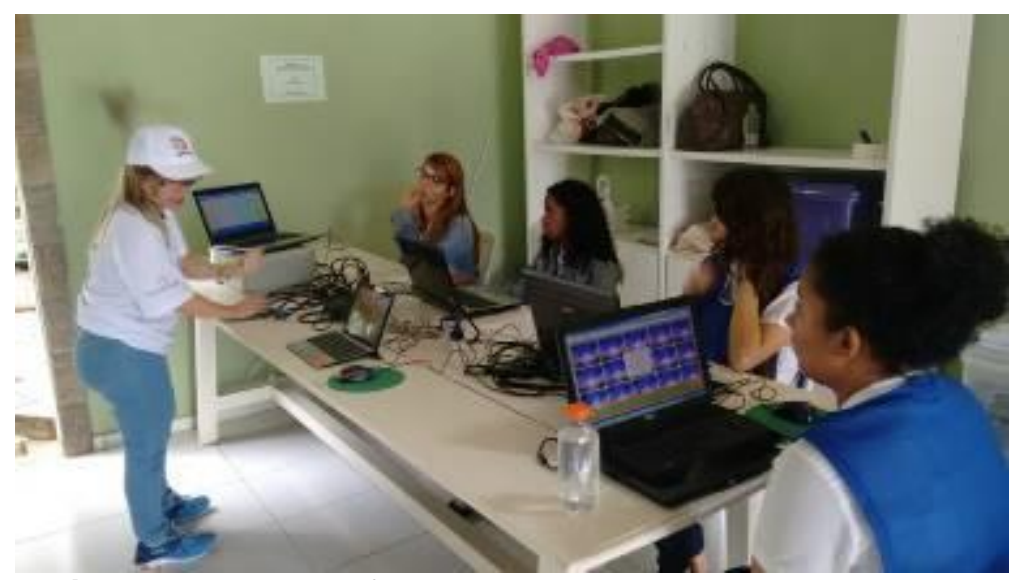

Figura 1: Mostra a oficina de jogos computacionais. 
Marques e colaboradores (2016) apontam que os jogos têm importante papel no ensino aprendizagem, justamente por promover a estimulação lúdica de processos neuropsicopedagógicos que envolvem aspectos neurológicos, psicológicos e pedagógicos, de tal forma que o jogar e o aprender, quando devidamente estimulados, tornam-se algo prazeroso.

Relato da equipe: "É, a gente achou muito legal a parte do jogo para levar e trabalhar com as nossas crianças. Porque a gente com a idade que tem, a gente achou muito divertido. As crianças, então, vão achar maravilhoso!

\section{Dinâmicas de grupos colaborativas}

A Figura 2 mostra os participantes atuando na oficina pedagógica: Dinâmica de grupos colaborativa.

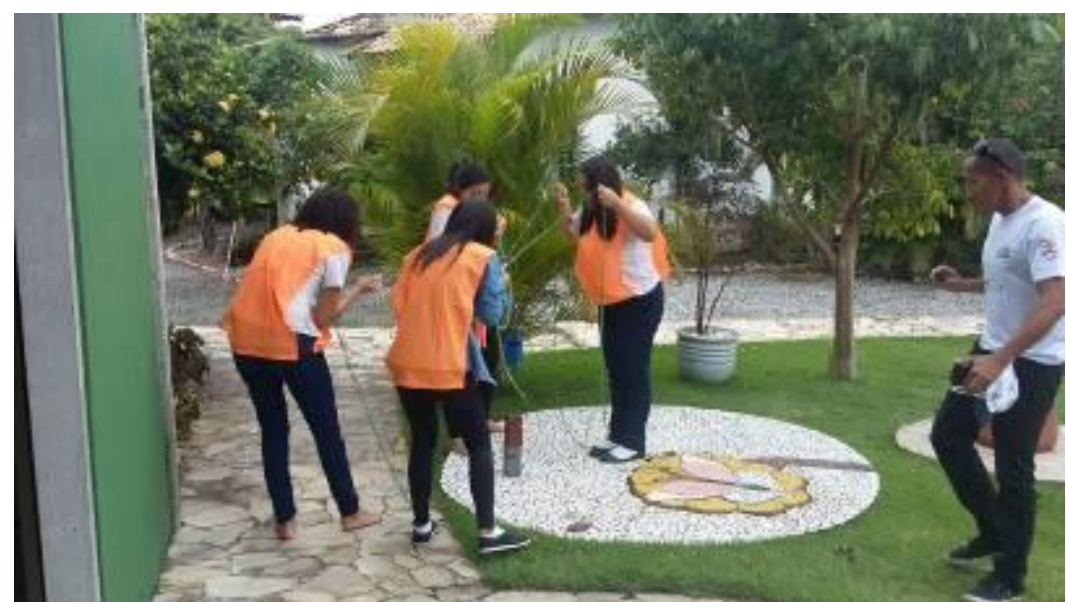

Figura 2: Oficina pedagógica Dinâmica de Grupos Colaborativa.

Para Correia (2006), cooperação tem a ver diretamente com colaboração, solidariedade e respeito entre as pessoas, e ao possibilitar que as crianças cooperem entre si, sem competição, elas percebem uma nova forma de jogar que melhora as interações sociais. Nos jogos cooperativos não existem erros, existem possibilidades de aprender e de forma divertida.

Relato da Equipe: "Nós aprendemos a cooperação, porque quando todo mundo faz algo junto é mais rápido, porque são várias cabeças pensando. Aprender com os erros, porque tiveram momentos em que a gente errou, e a gente descobriu porque a gente errou depois. 


\section{Oficina de "Contação de histórias"}

histórias".

A Figura 3 mostra os participantes durante a oficina de "Contação de

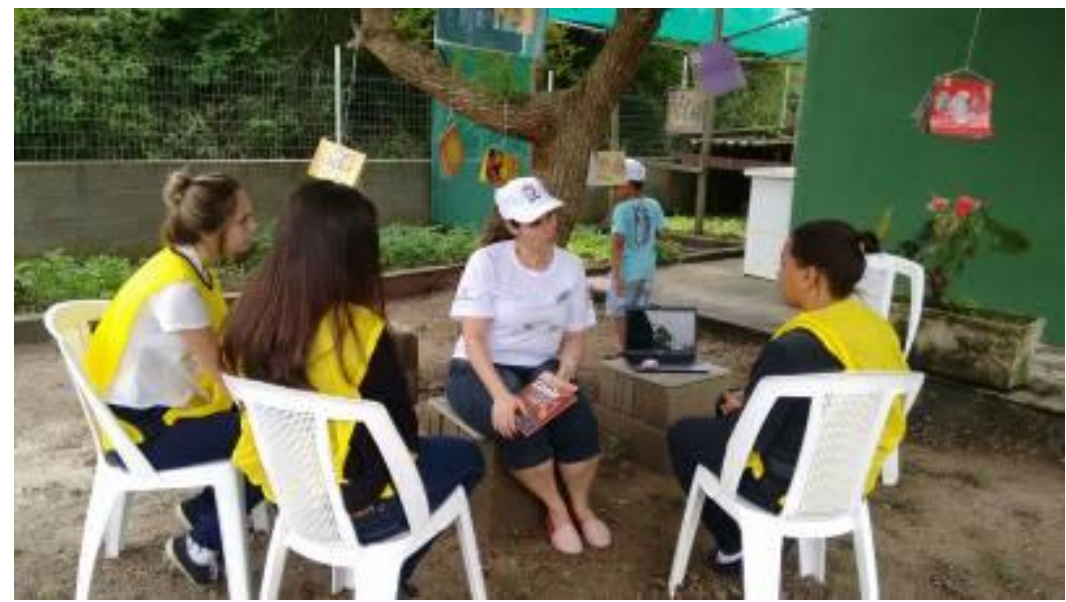

Figura 3: Oficina pedagógica Dinâmica de Grupos Colaborativa.

Pastorello e colaboradores (2015), reforçam que o hábito da leitura e da estratégia de contação de histórias, enquanto narrativas verbais, geram novas experiências e possibilitam inúmeras emoções que reforçam o processo de aprendizagem. Portanto, esta prática deve ser um convite a imaginação e a criatividade.

Relato da equipe: "É, a gente aprendeu muita coisa que a gente não sabia, a questão do tijolo ecológico, é... a questão do dinheiro ser reutilizado e tal".

\section{Atividade prática de plantio e cultivo}

A Figura 4 mostra os estudantes plantando as sementes de hortaliças na terra.

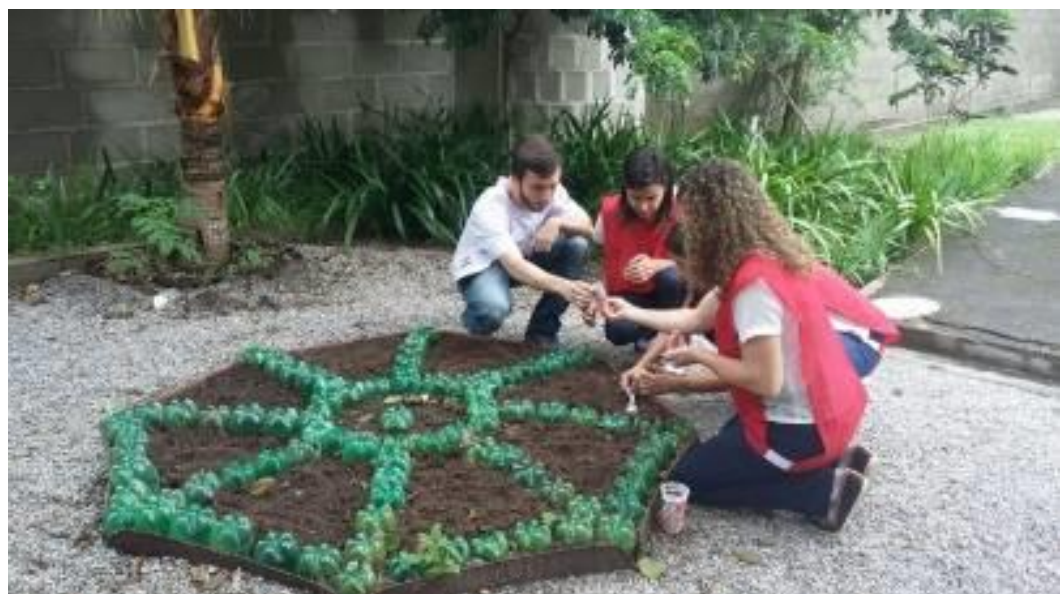

Figura 4: Estudantes plantando as sementes de hortaliças na terra e nos copos plásticos. 
Segundo Morgado e Santos (2008), em suas considerações finais, afirmam que a atividade de Educação Ambiental envolvendo o plantio de hortaliças é um laboratório vivo, capaz de unir teoria e prática de forma contextualizada transformando os alunos em agentes transformadores da sociedade.

Relato da Equipe: "Coisas que a gente nem imaginava que podia haver, e agora a gente já sabe. Como plantar, e tudo mais. E também a gente percebeu que através de cada pessoa que está aqui a ideia vai se propagando, porque cada um vai falar para o outro, e o outro, e assim pode ser tornar uma sociedade melhor".

\section{Lições aprendidas}

Ao final das quatro oficinas, as equipes se reuniram no salão principal para discutir as lições aprendidas durante a visita ao projeto de Educação Ambiental. Durante 15 minutos os grupos refletiram sobre o que aprenderam e quais ações podem implementar na vida cotidiana. Depois, tiveram mais 15 minutos para apresentarem suas observações e reflexões.

Segundo Guimarães (2007), a Educação Ambiental crítica acontece em um ambiente educativo, para além dos muros da escola, em que a aprendizagem se dá em um processo de construção de conhecimentos vivenciais embasada pelo princípio participativo. A diretriz pedagógica deve ocorrer no sentido de estimular a reflexão e a ação diante de situações problematizadoras da realidade social do aluno.

Relato da Equipe Amarela: "Então aqui, nós aprendemos a reutilizar, a reciclar e a plantar. Mas, o que eu e o meu grupo chegamos à conclusão foi que, para levar para nossa vida, é que mesmo que nós sejamos um em um milhão, um em um bilhão, nós devemos fazer a diferença. Só assim que o mundo vai evoluir, e o mundo evoluindo, nós vamos evoluir enquanto pessoas, como seres humanos".

\section{Discussões}

Um dia após a execução do Projeto de Educação Ambiental, foi realizada uma pesquisa, e aplicado um questionário aos alunos, pelas orientadoras educacionais, do Instituto de Educação Ismar Gomes de Azevedo (IGA), que teve como objetivo avaliar as percepções dos estudantes em relação a visita feita ao projeto. $O$ resultado desta pesquisa foi gentilmente cedido pela direção da escola (IGA, 2016) para contribuir com o desenvolvimento desta pesquisa. 12 (doze) participantes responderam ao questionário. A participação na pesquisa foi de caráter voluntário e os respondentes não foram identificados, desta forma preserva-se o resguardo do anonimato. 


\section{Coleta e análise dos dados}

Ocorre maior concentração de estudantes entre 17 e 18 anos de idade, com um percentual de $60 \%$ das pessoas nessa faixa. Outro ponto de destaque é a participação exclusiva do gênero feminino na pesquisa. Embora na escola de formação de professores sejam encontrados estudantes do gênero masculino, eles são minoria.

Pergunta 1: Você percebe diferença na paisagem das praias da cidade em épocas de alta e baixa temporada?

Resultado obtido: Todos disseram que percebem diferença na paisagem das praias.

Segundo Gouveia (2012), a adequada destinação dos resíduos sólidos é uma estratégia que contribui para a preservação do meio ambiente, da melhoria qualidade de vida e de saúde da população, além de tornar a paisagem atrativa. É notória uma maior concentração de resíduos dispostos de forma inadequada na cidade de Cabo Frio, nos períodos de alta temporada.

Pergunta 2: Que atitudes você acha que as pessoas deveriam tomar para melhorar esta situação?

O quadro 2 concentra as respostas em relação à pergunta de número 2 .

Quadro 2: Concentra as respostas em relação à pergunta de número 2.

\section{Estudante}

1

2

3

4

5

6

7

8

9

10

11

12
Respostas

Elas deveriam levar sacolas para retirar e separa seus lixos

Consciência do impacto do lixo e mudança de hábitos

Cada uma tomar conta do lixo que produz. Descartando-o de maneira adequada

Descartar o lixo corretamente

Descartarem corretamente o lixo

Destinar melhor os resíduos por elas produzidos

Ter consciência, guardar todo o lixo que foi produzido e jogar na lixeira

Cada um jogar seu lixo na lixeira

Ter mais consciência

Não deveriam jogar lixo nas ruas

Optando por transportes como bicicleta, descartando o lixo corretamente, etc.

Começar a se conscientizar e fazer a diferença

Diante deste cenário, Rocha e colaboradores (2012) afirmam que é fundamental estabelecer uma relação direta entre gestão de resíduos sólidos e Educação Ambiental com a finalidade de minimizar os impactos no meio ambiente decorrentes dos efeitos antrópicos. Também é preciso que ocorram

Revbea, São Paulo, V. 13, № 2: 372-387, 2018. revista brasileira 
ações constantes, por parte do governo e da mídia, de sensibilização em relação as questões ambientais. A gestão dos resíduos sólidos é um tema que precisa ser constantemente discutido pela sociedade civil.

Pergunta 3: Após a visita ao projeto você percebeu alguma mudança de atitude sua em relação ao meio ambiente?

Resultado obtido: $80 \%$ dos estudantes declararam terem mudado a atitude em relação a percepção do meio ambiente.

Sauvé (2016) aponta que a Educação Ambiental sensibiliza as pessoas no sentido de serem mais responsáveis com os recursos da natureza, sendo este o desafio ético e político mais exigente e mais fundamental de nossas sociedades.

\section{Conclusão}

Este estudo possibilitou implantar um projeto de Educação Ambiental com objetivo de sensibilizar os estudantes em relação a realidade socioambiental do município de Cabo Frio-RJ. Acrescentamos que, além da destinação adequada dos resíduos sólidos urbanos, também é importante investir em educação. Sobretudo, em uma proposta pedagógica da Educação Ambiental crítica, articulada com o desenvolvimento de projetos fora da sala de aula formal e que tenha como prática o caráter educativo crítico.

Nesse sentido, os jogos educacionais realizados por meio do Ciclo de Atividade Vivencial (CAV), organizado em forma de oficinas pedagógicas, são um processo prático de ensino aprendizagem que permite o desenvolvimento de novas habilidades, uma vez que proporcionam o debate, estimulam 0 pensamento crítico e resultam em mudança de comportamento. Foi possível observar, que por meio das narrativas dos estudantes do 3 o ano do ensino médio, após percorrem as quatro oficinas pedagógicas do projeto "Oficina da Terra", houve uma mudança significativa na percepção e sensibilização em relação às questões socioambientais.

Diante disso, podemos concluir que a utilização do Ciclo de Atividade Vivencial (CAV) organizado em oficinas pedagógicas representa uma importante estratégia no processo de ensino-aprendizagem. O que propicia aos estudantes a construção de uma prática educativa, onde possam refletir sobre seus comportamentos em relação ao meio ambiente e à sociedade, e para que tenhamos condições de oferecer um futuro melhor para essa e as demais gerações.

\section{Referências}

ABRELPE (Associação Brasileira de Empresas de Limpeza Pública e Resíduos Especiais). Estimativas dos custos para viabilizar a universalização da destinação adequada de resíduos sólidos no Brasil. São Paulo, jun. 2015. (Visitado em 30 de novembro de 2016) <Disponível em:<http://www.abrelpe.org.br/arquivos/pub estudofinal 2015.pdf>

Revbea, São Paulo, V. 13, № 2: 372-387, 2018. 
BRASIL. Decreto lei no 9.795, de 27 de abril de 1999. Disponível em: $<$ http://www.siam.mg.gov.br/sla/download.pdf?idNorma=491>. acesso em 28 de novembro de 2016.

BRASIL. Lei 9.394, de 20 de dezembro de 1996. Estabelece as Diretrizes e Bases da Educação Nacional. Disponível em <https://www.planalto.gov.br/ ccivil 03/Leis/L9394.htm> acesso em 28 de novembro de 2016.

BRASIL. Lei № 12.305, DE 2 DE AGOSTO DE 2010. Institui a Política Nacional de Resíduos Sólidos [acesso em acesso em 30 de novembro de 2016] Disponível em: <http://www.planalto.gov.br/ccivil 03/ ato20072010/2010/lei//12305.htm>.

BRUM, J. Cabo Frio: Conhecer para Preservar. Cabo Frio: Completa, 2015.

CABO FRIO, Lei Orgânica do Município de Cabo Frio, publicada em 20 de abril de 1990. Artigo 160 - Assegura o direito à qualidade de vida e à proteção do meio ambiente. Disponível em: <http://www.cabofrio.ri.gov.br/ municipio/legislacao > acesso em 22 de agosto de 2016].

CARVALHO, I.C.M. Educação Ambiental crítica. Nomes e endereçamentos da educação. Brasília: Ministério do Meio Ambiente, p. 13-24, 2004.

CASARIN, H.C.S. Pesquisa científica: da teoria à prática. Curitiba: Intersaberes, 2012.

CORREIA, M.M. Jogos cooperativos perspectivas, possibilidades e desafios na educação física escolar. Rev. Bras. Cienc. Esporte, Campinas, v. 27, n. 2, p. 149-164, jan. 2006.

DELPHINO, M.G.B. et al. A importância da contação de história para o desenvolvimento cognitivo, social, emocional e afetivo da criança na educação infantil. RIT-REVISTA INOVAÇÃO TECNOLÓGICA, v. 6, n. 2, p. 05-25, 2016.

FERREIRA, S.F.M.; MIRANDA, A.C.; GOMES, H.P. Um estudo de uma comunidade de trabalhadores em salinas: o impacto ambiental e uma proposta em educação ambiental. Revista Científica ANAP Brasil, v. 8, n. 10, 2015.

GOUVEIA, N. Resíduos sólidos urbanos: impactos socioambientais e perspectiva de manejo sustentável com inclusão social. Ciência \& Saúde Coletiva. Rio de Janeiro, v.17, n.6, p. 1503 - 1510. 2012.

GUIMARÃES, M. Educação Ambiental crítica. Identidades da Educação Ambiental brasileira. Brasília: Ministério do Meio Ambiente, p. 25-34, 2004.

GUIMARÃES, M. Vamos Cuidar do Brasil. Educação Ambiental: participação para além dos muros da escola. Brasília: Ministério da Educação, Coordenação Geral de Educação Ambiental, p. 95- 102, 2007. Disponível em <http://www.ibram.df.gov.br/images/Educa\%C3\%A7\%C3\%A30\%20Ambiental/U NESCO $\% 20$ E $\% 20$ MEC $\% 20 \% 20$ Vamos $\% 20$ cuidar\%20do\%20Brasil.\%20Concei tos\%20e\%20Pr\%C3\%A1ticas\%20em\%20Educa\%C3\%A7\%C3\%A30\%20Ambie ntal\%20na\%20Escola.pdf.> acesso em 22 de novembro de 2016. 
IBGE - Instituto Brasileiro de Geografia e Estatística. Censo $2014 .$. Disponível em: www.cidades.ibge.gov.br/xtras/temas.php?lang=\&codmun= 330070\&idtema $=16 \&$ search $=\|$ s\%EDntese-das-informa\%E7\%F5es $>$ acesso em 04 de abril de 2016.

IGA. Escola Estadual Ismar Gomes de Azevedo. Documento interno: Questionário de visita ao projeto de Educação Ambiental. 2016.

INEP - Instituto Nacional de Estudos e Pesquisas Educacionais Anísio Teixeira. Censo Escolar 2015. Disponível em $<$ http://matricula.educacenso.inep.gov.br/controller.php $>$ acesso em 22 de dezembro de 2016.

KOLB, D.A. Experiential learning: experience as the source of learning and development. EUA: Prentice-Hall, 1984.

LOUREIRO, C.F.B. Identidades da Educação Ambiental brasileira. Educação Ambiental Transformadora. Ministério do Meio Ambiente. Diretoria de Educação Ambiental; Philippe Pomier Layrargues (coord.). - Brasília: Ministério do Meio Ambiente, 2004.

MARQUES, C.V.M. et al. Games Inteligentes: Investigação Científica por Jogos Computacionais. Revista de Informática Aplicada, v. 11, n. 1, 2016.

MAYER, C. O poder de transformação: Dinâmicas de grupo. Campinas: Papirus, 2007.

MOTTA, A.; TERRA, R. Esporte, lazer e políticas públicas na Região dos Lagos. Rio de Janeiro: Iventura, 2011.

MOURA, R.P. E o mar vai virar aterro - antropologia, direito e conflito nas disputas por espaços num bairro do interior fluminense. Encontro Nacional de Antropologia do Direito, São Paulo, 2011.

OLIVEIRA, C.L. Significado e contribuições da afetividade, no contexto da Metodologia de Projetos, na Educação Básica. CEFET-MG. Belo Horizonte, 2006.

OLIVEIRA, C.P. Lixo: Problemas, caminhos possíveis e práticas diárias na percepção do cidadão. Rio de Janeiro, 2011.

OLIVEIRA, M.A.; SAUAIA, A.C.A. Impressão docente para aprendizagem vivencial: um estudo dos benefícios dos jogos de empresas. Administração: Ensino e Pesquisa, v. 12, n. 3, p. 355-391, 2011.

PASTORELLO, M.C.; ANGELO, A.A.; TORRES, S.P. A importância da "contação" de histórias para o processo de alfabetização e na formação de leitores. Vol. 6, fevereiro a julho 2015. Disponível em: $<$ http://docplayer.com.br/9687158-A-importancia-da-contacao-de-historias-parao-processo-de-alfabetizacao-e-na-formacao-de-leitores-resumo.html> acesso em 26 de outubro de 2016.

PEREIRA, R.C.S. O desenvolvimento de jogos computacionais como uma estratégia de ensino- aprendizagem em Educação Ambiental. Niterói, 2014.

Revbea, São Paulo, V. 13, № 2: 372-387, 2018. 
PEREIRA, R.C.S.; DE MIRANDA, A.C. O jogo computacional: o desenvolvimento e os desafios da aprendizagem envolvendo temas ambientais. Revista Científica ANAP Brasil, v. 8, n. 10, 2015.

PERS/RJ - Plano Estadual de Resíduos Sólidos do Rio de Janeiro. Publicado em agosto de 2014. [acesso em 05 de abril de 2016]. Disponível em; $<$ http://www.ri.gov.br/web/sea/exibeconteudo?article-id=1941406>

PMCBF - Prefeitura Municipal de Cabo Frio. Disponível em: $<$ www.cabofrio.ri.gov.br/servicos/voce/servicos-publicos $>$. Acesso em $05 \mathrm{de}$ abril de 2016.

PMCBF - Prefeitura Municipal de Cabo Frio. Disponível em: $<$ www.cabofrio.ri.gov.br/noticia/cabo-frio-esta-com-100-de-ocupacaohoteleira.2014>. Acesso em 06 de julho de 2016.

REZENDE, B.L.A. et al. A interdisciplinaridade por meio da pedagogia de projetos: uma análise do projeto "horta escolar: aprenda cultivando hortaliças" numa perspectiva CTSA. Revista Eletrônica Debates em Educação Científica e Tecnológica, V. 04, N. 01, p. 52 - 51, Junho, 2014.

ROCHA, M.B.; SANTOS, N.P.; NAVARRO, S.S. Educação Ambiental na Gestão de Resíduos Sólidos: Concepções e práticas de estudantes do curso superior de tecnologia em gestão ambiental. Ambiente \& Educação, 17 (1). 2012.

SAUVÉ, L. Viver juntos em nossa terra: desafios contemporâneos da educação ambiental. Revista Contrapontos, v. 16, n. 2, p. 288-299, 2016.

SECRETARIA DE ESTADO DA EDUCAÇÃO. Superintendência da educação diretoria de tecnologia educacional. Manual para uso do Jclick, Curitiba, 2010. Disponível em: clic.xtec.cat/docs/guia JClic br.pdf. Acesso em: 23 de novembro de 2016.

SEME - Secretaria Municipal de Educação de Cabo Frio. Diretrizes curriculares para Educação Ambiental. Cabo Frio, 2012. Disponível em: $<$ http://www.semecabofrio.net.br/wpcontent/uploads/2012/11/diretrizes curricul ares de educacao ambiental.pdf> Acesso em 22 de novembro de 2016.

SOUZA, B.C.P.; MENEZES, P.M.L. Os nomes geográficos do município de Cabo Frio-RJ. XIV Congresso Nacional De Linguística e Filologia. Cadernos do CNLF, Vol. XIV, № 02. Rio de Janeiro. 2010

VALADÃO, I.C.R.P. Manual do tijolo ecológico com reaproveitamento de resíduos. FERP. Volta Redonda. 2015. 